\title{
Lifting of biogenic compounds by a riverbed from a municipal drainage basin on a day scale
}

\author{
Anna Fortuniak ${ }^{1}$, Krzysztof Hałas $^{2}$, Michat Górecki ${ }^{3, *}$, Krzysztof Szewczyk ${ }^{2}$, \\ Angelika Wojtania $^{2}$, and Maciej Ziułkiewicz ${ }^{1}$ \\ ${ }^{1}$ Laboratory of Geology, University of Łódź, 90-139 Łódź, ul. Narutowicza 88, Poland \\ ${ }^{2}$ Third year of full-time studies in the field of Geomonitoring, the Faculty of Geographical Sciences, \\ University of Łódź, 90-139 Łódź, ul. Narutowicza 88, Poland \\ ${ }^{3}$ Third year of doctoral studies, the Faculty of Geographical Sciences, University of Łódź, 90-139 Łódź, \\ ul. Narutowicza 88, Poland
}

\begin{abstract}
Urban river is the object of very dynamic hydrochemical changes. It was decided to trace the variability of physicochemical elements within 24-hour. One of the rivers in Łódź - Olechówka - was selected for research, where, having knowledge from previous research, two measurement-control points were established: first located in the middle course of the river (on its quasi-natural fragment), second at its mouth to the recipient. Between these points, the Olechówka River catchment gains significantly on urbanization. A measurement series during 24-hour was carried out at each of the points, during which in situ measurements $\mathrm{Q}, \mathrm{T}$, $\mathrm{pH}, \mathrm{SEC}$ and $\mathrm{O}_{2}$ were taken every 1 hour and water samples were taken for the analytical determinations $\mathrm{NO}_{3}{ }^{-}, \mathrm{PO}_{4}{ }^{3-}, \mathrm{NH}_{4}{ }^{+}, \mathrm{TN}, \mathrm{TP}$ and Susp. With relatively stable hydrological conditions, a twenty-four hour cycle of changes in nutrient concentrations was observed, whose maxima occur during the night hours.
\end{abstract}

\section{Introduction}

Rivers flows in an urban area are generally an integral part of the city's drainage system. Protection of rivers against pollution causes that their riverbeds are free from domestic sewage, but not from rainfall sewage or pollution flowing out with installations of drainage of built-up areas. Incorporation rivers into the sewage system causes that pollutions deposited in the catchment with rainfall, dry deposit or flowing out with drainage systems from the drained soil profile flow into the river. These additional functions clearly burden urban rivers, making them a form far removed from its natural characters. They become practically, in every aspect their hydrological and hydrochemical characteristics, the object of very dynamic transformations and processes. This makes us treat the urban river as a peculiar object of observation, requiring a non-standard research approach. Laboratory of Geology of the University of Łódź has been working for several years to obtain a hydrochemical image of

\footnotetext{
${ }^{*}$ Corresponding author: michal.gorecki@geo.uni.lodz.pl
} 
the urban river in a various methodical scenes. The image of pollution of the Olechówka River during flash flood was captured during the first research season in 2015 [1]. Hydrochemical changes of river water during flow from its "sources" to the estuary were documented in the second research season in 2016 [2]. The third season was devoted to 24-hour physicochemical observation conducted on the Olechówka River at two measurement-control points. This paper presents the results of this work. The main goal of multi-seasonal research of the Olechówka River is to develop the basis for verification of the methodology for monitoring the chemical status of urban rivers. According to [3] and [4] water samples collected on working days (from 8:00 to 18:00) do not show the full dynamics of the processes taking place in the catchment and riverbed and may not take into account the maximum concentration of parameters. Diurnal measurements show that the use of instantaneous measurement, as a 24-hour value, may be subject to a very large error [5]. The biggest differences are in the case of total phosphorus, $\mathrm{NO}_{3}{ }^{-}$, dissolved oxygen, water temperature, SEC or $\mathrm{pH}[6,7]$.

Among the distinguished hydrochemical parameters is the representation of biogenic compounds. Therefore, there is a high probability of making a mistake in calculating the amount of nutrient load removed from the urban catchment, made on the basis of instantaneous measurements, treated as average. It becomes necessary to know the scale of diurnal fluctuations in nutrient concentrations and correction of the applied methodology for testing the quality of urban rivers.

The research of the Olechówka River carried out in 2015, during the flash flood, showed that the biogenic compounds are being removed from the urban catchment at various rates [1]. Work implemented in 2016 showed that during the water flow from the "sources" to the estuary, nitrate and phosphate concentrations decrease with the elongation of the water runoff time, and nitrates additionally with the increase of the discharge rate [2].

\section{Material and methods}

The image of 24-hour changes of biogenic concentrations in the Olechówka River will largely complement the results of earlier hydrochemical observations of this river. In 2016, measurements were performed at various times of the day, i.e. from 7:00 until 23:25. Are the effect of 24-hour changes hidden in the changes registered at that time?

The research in 2017 was conducted within two 24-hour cycles of observation, on May $17^{\text {th }}$ and May $31^{\text {st }}$, on two different measurement-control points (mcp). The first one is located at the Zygmunta Street (ZM), the second one at the Podmokła Street (PD) (Fig. 1). PD represents the estuary section of the river, while $\mathrm{ZM}$ represents is the most naturally preserved part of the Olechówka River and the only one in which in 2016 the process of autopurification has been documented [2]. The characteristics of subcatchment closed with both mcp are presented in Table 1. Between the first and the second observation cycle, 14 days elapsed, which approximately corresponds to the measurements of water flow time during the tests in 2016. According to them, the time of water runoff between ZM and PD is 10 days. The difference results from different hydrometeorological conditions and different time of water retention in Stawy Jana, a reservoir located between the designated mcp (Fig. 1). 


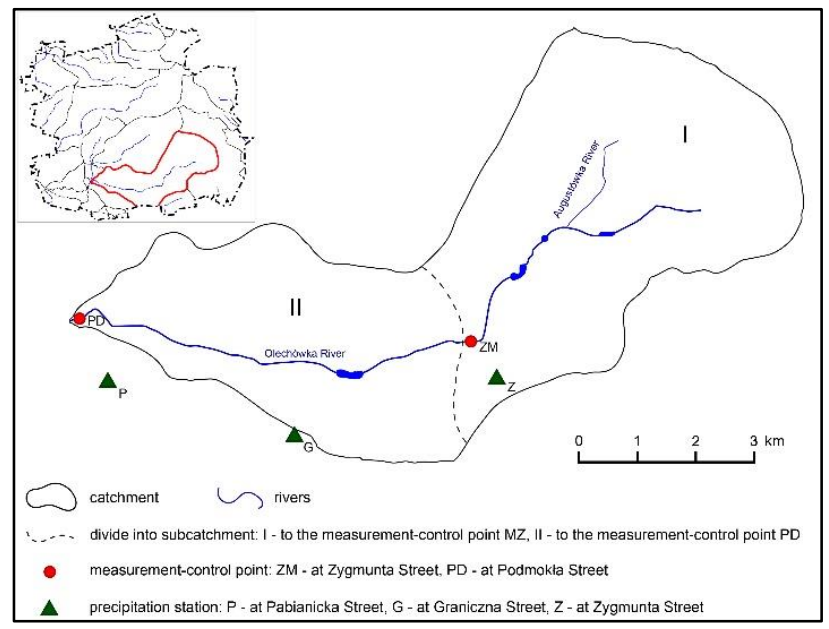

Fig. 1. Scheme of research organization in the Olechówka River catchment.

Water samples were taken every 1 hour to determine nitrates $\left(\mathrm{NO}_{3}{ }^{-}\right)$, orthophosphates $\left(\mathrm{PO}_{4}{ }^{3-}\right)$, ammonium ions $\left(\mathrm{NH}_{4}^{+}\right)$, total nitrogen $(\mathrm{TN})$, total phosphorus (TP) and total suspension (Susp.). During water sampling, the physicochemical parameters of water were measured in the range: water temperature (Temp.), $\mathrm{pH}$, standardized electrolytic conductivity (SEC) and dissolved oxygen $\left(\mathrm{O}_{2}\right)$. The hydrochemical observations were supplemented by the measurement of discharge rate $(\mathrm{Q})$ using the current meter. Chemical analysis of waters were performed at the laboratory of Laboratory of Geology and at the laboratory of Collective Sewage Treatment Plant in Łódź.

Table 1. Characteristics of the Olechówka River subcatchments.

\begin{tabular}{|c|c|c|c|}
\hline & I & II \\
\hline \multicolumn{2}{|c|}{ subcatchment area $\left[\mathrm{km}^{2}\right]$} & 22.85 & 16.15 \\
\hline \multicolumn{2}{|c|}{$\begin{array}{l}\text { part of subcatchment area in total } \\
\text { catchment area [\%] }\end{array}$} & 58.59 & 41.41 \\
\hline \multirow{7}{*}{$\begin{array}{l}\text { land use } \\
\text { within the } \\
\text { subcatchment } \\
{[\%]}\end{array}$} & residential areas & 10 & 50 \\
\hline & industrial areas & 25 & 20 \\
\hline & service areas & 10 & 10 \\
\hline & agricultural areas & 25 & 2 \\
\hline & green areas & 15 & 15 \\
\hline & forests & 2 & 0 \\
\hline & another & 13 & 3 \\
\hline \multicolumn{2}{|c|}{$\begin{array}{l}\text { number of outlets of sewage } \\
\text { collectors to the Olechówka River }\end{array}$} & 14 & 39 \\
\hline \multicolumn{2}{|c|}{ character of riverbed above mcp } & $\begin{array}{l}\text { regulated: } \\
\text { biological } \\
\text { reinforcement } \\
\text { (sandy bottom) }\end{array}$ & $\begin{array}{l}\text { regulated: only } \\
\text { heavy technical } \\
\text { reinforcements } \\
\text { (bottom lined with } \\
\text { concrete slabs) }\end{array}$ \\
\hline
\end{tabular}

\section{Results}

During the research period at the mcp and the time preceding them by 25 days, which resulted from the time of water inflow from the spring area to ZM, not observed in the precipitation stations located in the catchment and its immediate vicinity (Fig. 1) intensive precipitation which could have causes flood (Fig. 2). The sum of rainfall for 48 days was there from 93 to 
$95.5 \mathrm{~mm}$, which gives an average of nearly $2 \mathrm{~mm}$ per day. The size of the 5-day sum of rainfall, which is able to causes a local flood, i.e. $30 \mathrm{~mm}$ [8], was exceeded only on precipitation stations on 24-27.04.2017, when the water was above the group of retention reservoirs in the upper section of the Olechówka River (Fig. 1).

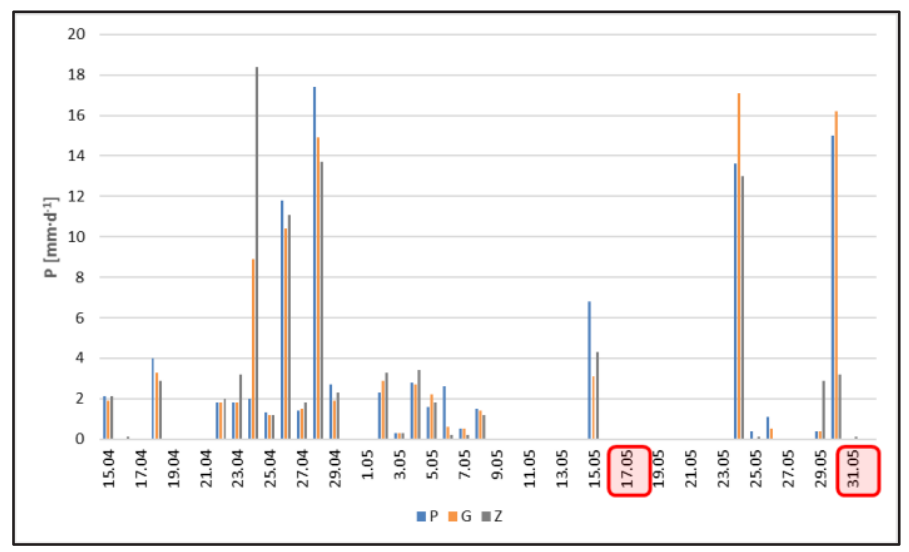

Fig. 2. Daily sums of rainfall in the southern part of Łódź during the water flow of the Olechówka River channel from the source area to the estuary, materials obtained from the Department of Meteorology and Climatology of the University of Łódź, the days of hydrochemical research have been distinguished.

Measurements of Q showed that on average twice water flow was less in ZM than in PD: $20.2 \mathrm{~L} \cdot \mathrm{s}^{-1}$ against $37.1 \mathrm{~L} \cdot \mathrm{s}^{-1}$; but daily flows, however, showed similar variability: $\mathrm{VC}_{\mathrm{ZM}}=9.6 \%$, and $\mathrm{VC}_{\mathrm{PD}}=8.2 \%$. Low values of the coefficient of variation indicate that the hydrological conditions during the 24-hour measurements were stable.

Wilcoxon matched-pairs test indicated that statistically significant differences $(\mathrm{p}<0.05)$ between $\mathrm{ZM}$ and $\mathrm{PD}$ occur in the case of SEC, $\mathrm{O}_{2}, \mathrm{TN}, \mathrm{NO}_{3}{ }^{-}, \mathrm{PO}_{4}{ }^{3-}$ and $\mathrm{NH}_{4}{ }^{+}$. The hydrochemical similarity is shown by Temp., TP and Susp. It is noteworthy that nutrient concentrations are clearly higher in PD than in ZM.

Comparison of $\mathrm{Q}$ with the values of hydrochemical elements in the correlation analysis showed statistically significant covariates in PD and the total lack of such relations in $\mathrm{ZM}$ - Table 2. With the Q in PD negatively correlate all, with the exception of TP, measures of nutrients and mineral salts.

Table 2. Correlation analysis of discharge rate of the Olechówka River in both mcp in relation to hydrochemical parameters; significant cases $(\mathrm{p}<0.05)$ were distinguished.

\begin{tabular}{|l|c|c|c|c|c|c|c|c|c|c|}
\hline Q in: & Temp. & SEC & pH & $\mathbf{O}_{2}$ & Susp. & TN & TP & $\mathbf{P O}_{4}{ }^{--}$ & $\mathbf{N H}_{4}{ }^{+}$ & $\mathbf{N O}_{3}{ }^{-}$ \\
\hline \multirow{2}{*}{ M } & -.2909 & .3662 & -.2461 & -.2149 & -.0348 & .0645 & -.0528 & .0539 & .2843 & -.0558 \\
\cline { 2 - 11 } & $p=.17$ & $p=.08$ & $p=.25$ & $p=.31$ & $p=.87$ & $p=.77$ & $p=.81$ & $p=.80$ & $p=.18$ & $p=.79$ \\
\hline \multirow{2}{*}{ PD } & .9058 & -.8597 & .6294 & .4406 & -.3397 & -.8996 & -.2147 & -.9014 & -.7258 & -.7749 \\
\cline { 2 - 11 } & $p=.00$ & $p=.00$ & $p=.00$ & $p=.03$ & $p=.10$ & $p=.00$ & $p=.31$ & $p=.00$ & $p=.00$ & $p=.00$ \\
\hline
\end{tabular}

The 24-hour changes in the values of hydrochemical parameters recorded in ZM and PD are presented in Figure 3 A, B. Distinct diurnal variability in $\mathrm{ZM}$ is characterized by Temp., the changes of which corresponds to the concentration of $\mathrm{O}_{2}$, Susp. and $\mathrm{NO}_{3}{ }^{-}$. In $\mathrm{PD}$, only $\mathrm{O}_{2}$ refers to the variability of the Temp.

In ZM, apart from elements showing variability, referring to the Temp., there is a second group whose elements exhibit a different - opposite to the first, diurnal course of changes in value. The image of mutual variation in $\mathrm{PD}$ is more complex than in $\mathrm{ZM}$. The opposite of the "thermal-oxygen" group is clearly represented by only TN and $\mathrm{NH}_{4}{ }^{+}$. In PD, subgroup Susp. 
and TP is clearly associated with the smallest oxygen content. SEC, $\mathrm{PO}_{4}{ }^{3-}$ and $\mathrm{NO}_{3}{ }^{-}$show a more individual course of value. SEC drastically increased in the last hour of observation, and nitrates showed a gradual increase until the occurrence of the smallest oxygen content, and later their concentrations were relatively stable. Interesting is the case of phosphates, the concentration of which increased sharply between 19:00 and 20:00 and remained at this level until the end of the observation, which coincides with the drop in the dissolved oxygen concentration in the Olechówka River and the first large "peak" of TP. The phenomenon of a sharp increase concentration of $\mathrm{PO}_{4}{ }^{3-}$ was also recorded in $\mathrm{ZM}$ between 21:00 and 22:00. Here too there was a clear - the biggest "peak" of TP at the moment when the concentration of $\mathrm{O}_{2}$ in water began to drop. The change in aerobic conditions in $\mathrm{ZM}$ coincides with a decrease in concentration of $\mathrm{NO}_{3}{ }^{-}$and an increase in $\mathrm{NH}_{4}^{+}$. The highest recorded concentration of $\mathrm{NH}_{4}{ }^{+}$in $\mathrm{PD}$ occurred at the time when $\mathrm{O}_{2}$ reached the absolute minimum.

A)

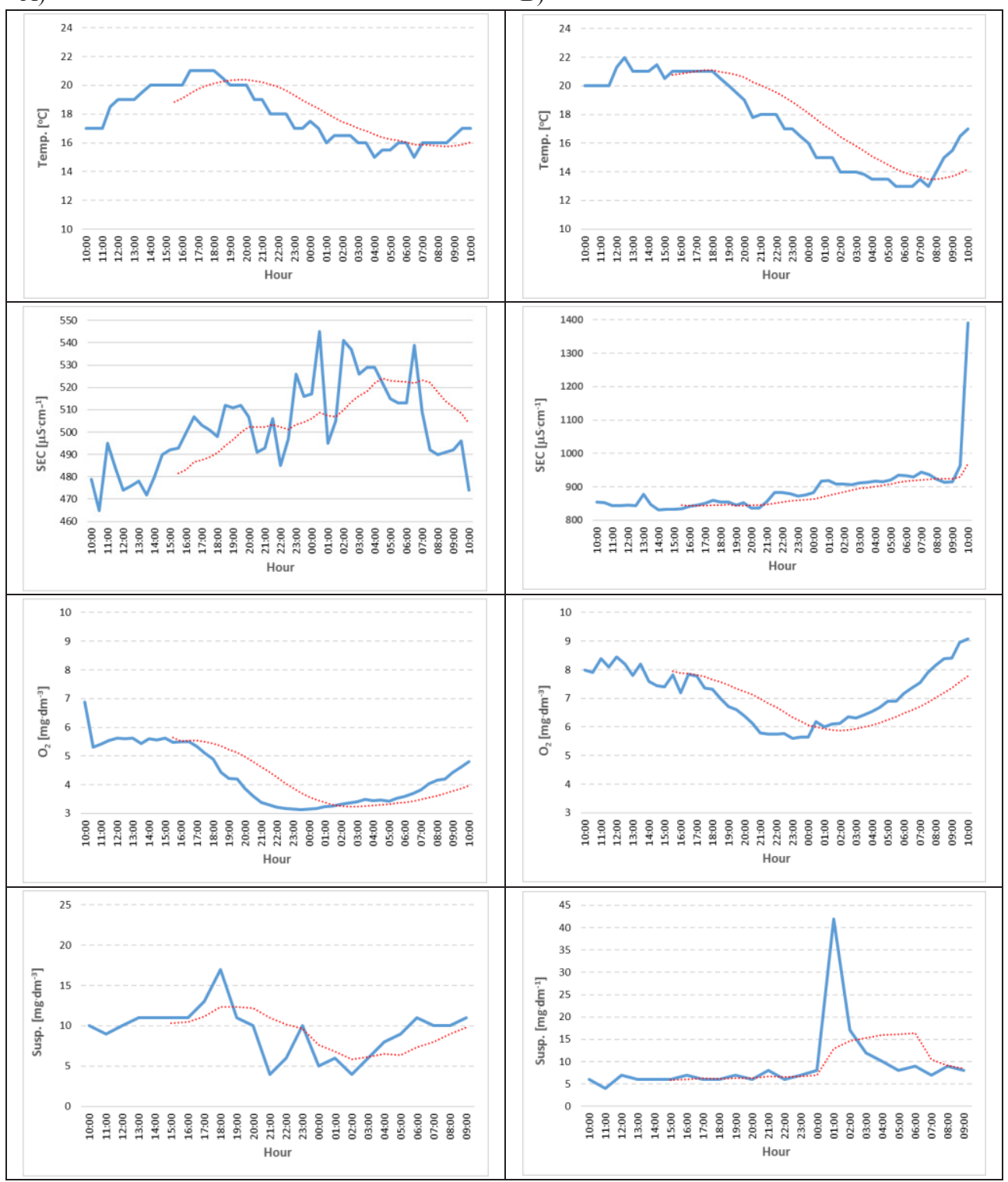




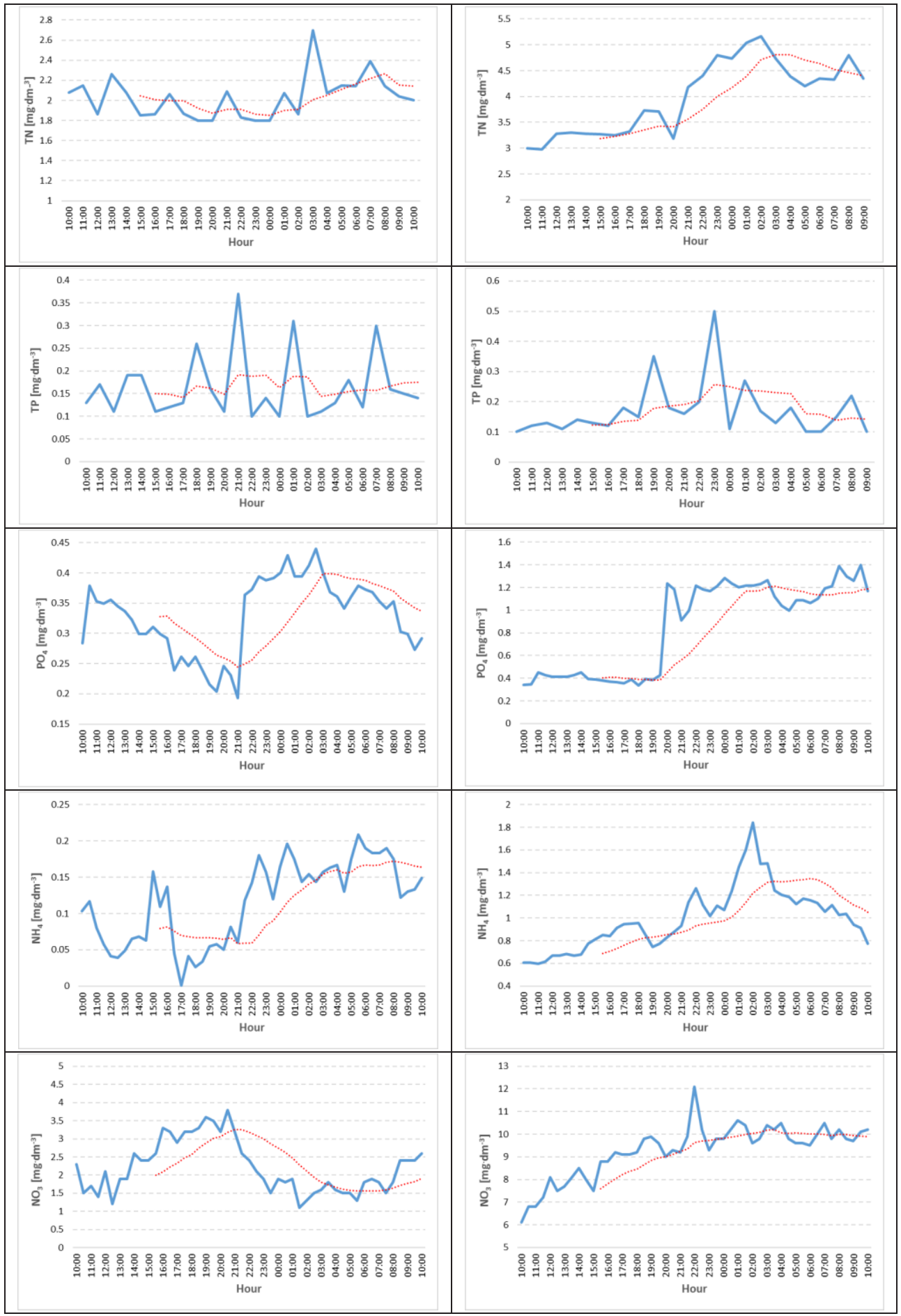

Fig. 3. Changes in the value of hydrochemical parameters on mcp: A - mcp at the Zygmunta Street (ZM), B - mcp at the Podmokła Street (PD); on the charts the moving average calculated from 6 elements is marked. 


\section{Discussion}

Changes of the hydrochemical elements values in $\mathrm{ZM}$, which closing the most natural section of the Olechówka River, reflects the processes of auto-purification of water. They are conditioned by light-thermal-oxygen factors, which in turn determine the transformations of biogenic compounds in the riverbed. The level of dissolved oxygen in water recorded in ZM is lower than in PD. It may be caused by shading of the riverbed by vegetation growing on the banks and effective drainage of groundwater (Table 1). Conversely, proportional changes in the oxygen dissolved in water in relation to the $\mathrm{NH}_{4}{ }^{+}$and proportional to $\mathrm{NO}_{3}{ }^{-}$, indicate the effective course of the nitrification and denitrification process in the 24-hour cycle. Lowering the oxygen concentration due to the reduction of phytoplankton photosynthesis and submerged plants results in the mobilization of phosphates from bottom sediments. This indicates the natural character of the river, in which the phosphate content regulates biological mechanisms [4]. The diurnal cycle of changes in phosphorus compounds is clearly visible in rivers with small flows [3], and such can include the Olechówka River. The phosphate activation phenomenon also occurred in the estuary section (PD). The conglomerate of basin and trough interactions occurring in the estuary section of the Olechówka River caused that the relation $\mathrm{O}_{2}-\mathrm{NH}_{4}{ }^{+}-\mathrm{NO}_{3}{ }^{-}$is not as readable as in $\mathrm{ZM}$. The effects of sewage sludge flow are marked here, as indicated by the increase in $\mathrm{NH}_{4}{ }^{+}$ concentrations, which is accompanied by a clear "peak" of the total suspension. A clear relationship between these hydrochemical elements was found in the Olechówka River research during the flood surge in 2015 [1]. A large number of cases of statistically significant correlation of hydrochemical elements with the discharge rate in PD (Table 2) indicates that the factor determining the chemical state is the amount of flowing water. In the case of the nitrogen content in water indicated above, this is a dilution effect, because all of these measures and $\mathrm{PO}_{4}{ }^{3-}$ also are negatively correlated with Q (Fig. 4).

A)

B)

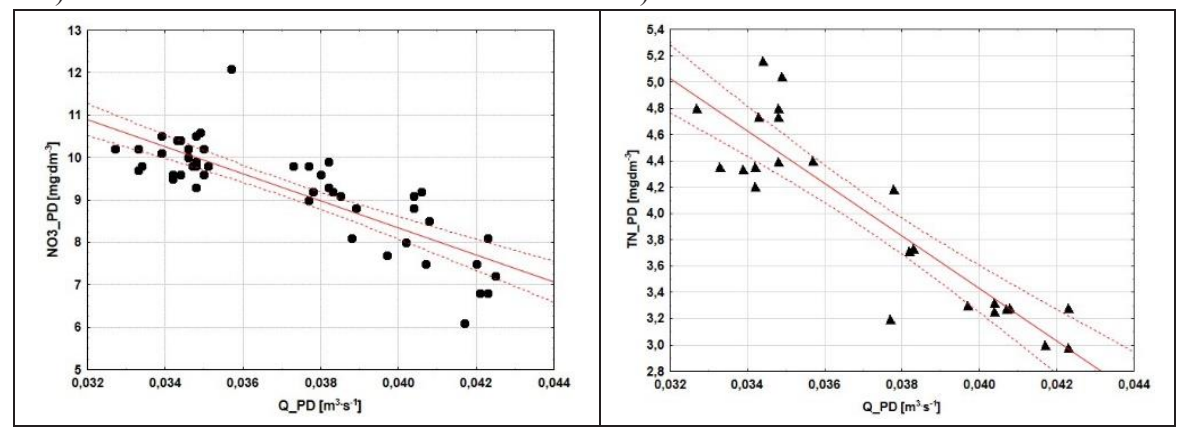

Fig. 4. Flow rate of the Olechówka River versus $\mathrm{NO}_{3}{ }^{-}$(A) and $\mathrm{TN}(\mathrm{B})$ concentrations in $\mathrm{PD}$; the confidence limit of $95 \%$ is marked.

The daily changes of hydrochemical elements indicates that the maximum values occur from 18:00 to 7:00 in ZM and between 19:00 and 10:00 in PD. It is worth noting that the most dynamic hydrochemical changes in the Olechówka River were recorded in the evening and at night. This translates into the result of the calculation of the load of nutrients flowing down of the Olechówka River. The result of calculations carried out on the basis of the diurnal intake result is clearly lower than if the calculation is based on the nightly consumption result in Table 3. The above comparison shows that the values that would be captured at the time of the day (8:00-18:00) are clearly lower than outside the "office" hours. 
Table 3. Comparison of the size of the daily nutrient load derived by the Olechówka River calculated on the basis of temporary extreme results with an indication of the time of their occurrence.

\begin{tabular}{|c|c|c|}
\hline Element & ZM (time) & PD (time) \\
\hline $\mathrm{TN}_{\min }[\mathrm{kg} \cdot 24$ hours $]$ & $2.65(12 \mathrm{AM})$ & $10.81(10 \mathrm{AM})$ \\
\hline $\mathrm{TN}_{\max }[\mathrm{kg} \cdot 24$ hours $]$ & $4.69(7 \mathrm{AM})$ & $15.34(2 \mathrm{AM})$ \\
\hline $\mathrm{TP}_{\min }[\mathrm{kg} \cdot 24$ hours $]$ & $0.16(3 \mathrm{PM})$ & $0.29(9 \mathrm{AM})$ \\
\hline $\mathrm{TP}_{\max }[\mathrm{kg} \cdot 24$ hours $]$ & $0.60(9 \mathrm{PM})$ & $1.50(11 \mathrm{PM})$ \\
\hline
\end{tabular}

\section{Summary}

1. The varied degree of urbanization of the Olechówka River catchment and the nature of land use make the transformation of the chemical composition of water along with the course of the river very quickly. Olechówka in PD shows a different hydrochemical image than in ZM. With relatively constant hydrological conditions prevailing during the research, the catchment is clearly visible, which in most hydrochemical elements was recorded at a higher level in the estuary section (PD) than the least transformed section (ZM).

2. In spite of the permanent anthropopressure in the waters of the Olechówka River, a daily cycle of changes in hydrochemical parameters is visible. In $\mathrm{ZM}$, the course of nitrification and denitrification processes is visible as a result of daily change of thermal-light-oxygen conditions. In PD, daily changes of nitrogen forms are suppressed by the effect of dilution, which is indicated by the strong correlation of hydrochemical elements with the flow rate.

3. Observed diurnal or even hourly dynamics of changes in physicochemical parameters causes that the "representative time" of sampling cannot be clearly indicated. The hydrochemical image of the Olechówka River during the day differs significantly from its nocturnal face, especially in relation to biogenic substances, especially at the point closing the entire catchment. Biogen loads calculated on the basis of daily (official) data are clearly lower than those calculated on the basis of data obtained during the night.

\section{References}

1. M. Ziułkiewicz, A. Fortuniak, A. Waack-Zając, M. Górecki, S. Grzędzińska, B. Małecka, Monografie Komitetu Gospodarki Wodnej Polskiej Akademii Nauk 39, 279-291 (2016)

2. T. Bagrowicz, A. Fortuniak, M. Górecki, M. Lewandowska, M. Ziułkiewicz, E3S Web of Conferences 17, 00002 (2017)

3. P. Jordan, R. Cassidy, Hydrol. Earth Syst. Sci. 15, 3093-3100 (2011)

4. E.J. Palmer-Felgate, H.P. Jarvie, R.J. Williams, R.J.G. Mortimer, M. Loewenthal, C. Neal, Journal of Hydrology 351, 87-97 (2008)

5. M. Ostojski, P. Wilk, J. Gębala, P. Orlińska-Woźniak, Polish Journal of Agronomy 22, 33-41 (2015)

6. S.R. Parker, C.H. Gammons, S.R. Poulson, M.D. DeGrandpre, Applied Geochemistry 22, 1329-1343 (2007)

7. J.P. Siwek, Zmienność składu chemicznego wód w małych zlewniach na progu Pogórza Karpackiego (Instytut Geografii i Gospodarki Przestrzennej UJ, Kraków, 2012)

8. W. Szalińska, G. Urban, I. Otop, Infrastruktura i Ekologia Terenów Wiejskich 9, 227-238 (2008) 